\title{
A Case Study of the Learning Retention of a Key Physics Concept among Undergraduate Physics Majors
}

\author{
Mitra Shojania Feizabadi, Anthony L. Troha \\ Department of Physics, Seton Hall University, South Orange, NJ, U.S.A.
}

\begin{abstract}
Assessing student learning is one of the practical methods which can gauge the effectiveness of different teaching approaches. The information obtained from the outcomes of such tests provide insights to potential instructional methods that can raise students' learning gains to a higher level and offer more impactful learning environments for them. The assessment of student learning is not limited to evaluating their gains during a specific course.

In this study, the learning retention of one of the key Physics concepts associated with Work and Energy was assessed through direct testing two years in a row among undergraduate Physics students after they were first introduced to that specific Physics concept.

The outcomes of this case study indicate that, as students progress from lower-level to upper-level courses in the Physics program, they will reach a better understanding related to the tested concept. This is significant as it shows a learning intervention in upper-level courses, stressing that the modification and application of previously learned concepts can lead to longer-lasting learning. This clarifies that connectivity among undergraduate Physics courses is one of the key factors for establishing a better understanding of the Physics concepts that students learn in the program.
\end{abstract}

\section{Introduction}

In undergraduate science programs, one of the effective ways to assess students' learning outcomes is to conduct pre- and post-assessment tests. This method can evaluate students' learning in a specific course [1], [2].

The previously developed assessment tests by peers in the field of Physics Education are mainly multiple-choice question tests that have been designed to assess student learning in different areas. Among various designed tests, we can point to the researchbased standard test of Force and Motion Conceptual Evaluation (FMCE), Brief Electricity and Magnetism Assessment test, or other tests which have been developed to evaluate student learning of different concepts in Physics [1], [2], [3], [4]. The assessment tests were designed to be administered to large groups of students. The results of pre- and postcourse evaluations provide us with a knowledge regarding the evolution of students' understanding of different Physics concepts among various groups of undergraduates. The outcomes of these tests led to the development of more impactful teaching strategies, such as interactive teaching styles [5], [6], [7].

This study goes beyond a course assessment and takes a closer look at the way in which the students' learning can be affected as they progress from lowerlevel to upper-level courses in the Physics program. The specific goal of this study is to assess learning retention among undergraduate Physics students.

The motivation for designing and conducting the assessment discussed in this work stemmed from our realization that students in the Modern Physics course express less familiarity with a general definition of Work as the integral over force multiplied by the infinitesimal element of displacement, and more in understanding that the Work is calculated by the direct multiplication of force by distance. After a year of taking the Principles of Physics lecture and the corresponding laboratory courses, it seemed that students, in specific cases, understood the definition of Work when the force was constant and the Work could be simply expressed by the multiplication of force by distance. It could be observed that they understood no clear distinction between forces that are constant and those that may vary by distance (i.e. spatially varying forces).

The root of this difficulty must stem from the failure to emphasize the integral definition of Work when applied to spatially varying forces, such as that associated with Hooke's Law [8]. Most textbooks introduce the notion of Work in terms of an algebraic definition involving a constant force and a distance [9], [10], [11], [12]. These texts then further the discussion by specifically examining spatially varying forces, and develop the integral definition of the Work as a necessary consequence of dealing with such forces. Some of the authors also demonstrate that the integral definition will yield the same answer as the algebraic variant when constant forces are considered, thereby denoting that the algebraic equation is a special case of the integral equation, so the latter is 
shown to be the general mathematical definition for Work [13], [14], [15].

This concern can potentially result from a number of factors, but ultimately hinges on the fact that if the integral definition is not well established in their minds, then the students tend to revert to the algebraic definition without realizing that it does not hold in all cases.

We learned, from this observed difficulty, that students usually express their understanding in the manner explained above, and, in order to gain a better understanding of students' learning retention as they progress in the program, we designed the method explained below, in which the long-lasting learning of students was assessed in a simple approach.

This method of assessment is not only beneficial in understanding the learning retention of students, but it can also identify the methods that can be implemented in order to make a strong connectivity among different courses in an undergraduate Physics course sequence. Below, the utilized methodology, the obtained results, their analysis, and suggestions for the enhancement of teaching methods are discussed.

\section{Methodology}

To conduct this assessment-based research project, we decided to focus on one of the concepts that Physics students learn during their freshman year. In this year, students usually take two parts of Principles of Physics. The course sequence is designed to cover the introductory concepts of Classical Physics. The first part of the two-semester sequence focuses on the concepts related to Newtonian Mechanics.

The students' performance was evaluated twice during the undergraduate program: the first time, one year after taking the introductory level course, Principles of Physics I, and the second time, two years after taking this course.

An assessment test of three questions was structured; the questions are listed in Subsection 2.2.

The students were tested on the first day of classes. No time restriction was implemented for students to answer to questions; however, in each round of testing, students were able to complete the test in fewer than 30 minutes.

\subsection{Ethical Considerations}

We took the following steps to fulfill requirements related to ethical considerations and the regulations set in the Family Educational Rights and Privacy Act of 1974 (FERPA) (U.S. Code, Title 20, Chapter 31, Subchapter III, Part 4, § 1232g; CFR, Title 34, Subtitle A, Chapter I, Part 99): The test was conducted anonymously. No names, student identification numbers, or personal information of any kind was collected along with this test. The assessment test did not have any bearing on the final grades of any course. The test was conducted on paper. The faculty member who conducted and collected the test, was the only member with access to the test results. It should be noted that the students' identifications were not even disclosed to that faculty member. The data was collected and analyzed as a whole. The results have been reported in the format of mean \pm SEM. Analysis of the results of individual students was not a factor in this study.

\subsection{Assessment Test}

In our approach, we developed an assessment test that contains three questions. In the first question, students were asked to explain the way in which the Work done on an object can be calculated. This question was specifically formulated to ascertain the students' immediate impressions regarding the definition of Work. In the second part of the first question, we asked whether the method that they explained can be implemented in all physical situations, and if not, we asked them to provide an example. This was intended to evaluate their understanding of the general definition of Work when applied to spatially varying forces.

The second question asked students to assume that one end of a spring with a spring constant $\mathrm{k}$ is affixed to a wall, and an object with a mass $\mathrm{M}$ is pushing or pulling on the other end of the spring in such a way that the object is horizontally from $\mathrm{x}=\mathrm{x} 1$ to $\mathrm{x}=\mathrm{x} 2$. Then, the students were asked to calculate the Work done on the object. In this question, we explicitly introduced the notion of a spatially varying force to evoke their memories to the fact that some forces are not necessarily constant in magnitude or direction.

In the third question, we asked students to express the formula for the associated Potential Energy stored in the system described in the second question. The goal of this question was to observe if the students recognized an inconsistency between their answer to this question and that of the previous question in the event that they had incorrectly answered the second question by employing the algebraic definition of Work rather than the integral one when they conducted the calculation.

\subsection{Scoring Rubric}

The rubric expressed in table 1 was then developed to provide us with a frame that can lead to consistent grading. The rubric included above was constructed in order to grade and evaluate the students' answers for each question. The total of 5 points was considered for each question and the 
Table 1. Scoring Rubric

\begin{tabular}{|c|c|c|}
\hline Question & Distribution of Scores & Point \\
\hline 1 & $\begin{array}{l}\text {-The work was expressed as integral over force. dx. } \\
\text {-The work was expressed as f.d. However, it was identified that this can't be } \\
\text { implemented in all cases. } \\
\text {-The work was expressed as f.d. However, it was identified that this can be implemented } \\
\text { in all cases. } \\
\text {-The work was identified as the multiplication of weight by distance. It was identified } \\
\text { that this can't be implemented in all cases. } \\
\text {-The work was identified as some correlation between force and distance, but not in a } \\
\text { correct format } \\
\text {-Wrong/no answer }\end{array}$ & $\begin{array}{l}5 \\
4 \\
3 \\
2 \\
1 \\
0\end{array}$ \\
\hline 2 & $\begin{array}{l}\text {-The work was corrected calculated with the result of } 1 / 2 \mathrm{kx}^{2} \\
\text {-The approach was correct, but the integral was not correctly calculated } \\
\text {-The work was calculated based on answer III of question } 1 \\
\text {-The force was not recognized correctly for the further procedure } \\
\text {-Some correct explanations } \\
\text {-No/wrong answer }\end{array}$ & $\begin{array}{l}5 \\
4 \\
3 \\
2 \\
1 \\
0\end{array}$ \\
\hline 3 & $\begin{array}{l}\text {-The potential energy was expressed correctly and was consistent with work } \\
\text {-The potential was correct but not consistent with the work that the student expressed in } \\
\text { Q2 } \\
\text {-The potential was not correct but the student knew that it should be equal to the work } \\
\text {-The students identified that the potential energy is not equal to the gravitational } \\
\text { potential energy and depends on the displacement and the spring stiffness. However, } \\
\text { they couldn't express the correct format of that } \\
\text {-Some possible correct explanations } \\
\text {-No/wrong answer }\end{array}$ & $\begin{array}{l}5 \\
4 \\
3 \\
2 \\
1 \\
0\end{array}$ \\
\hline
\end{tabular}

distribution of the points for each question has been reflected in this rubric.

\section{Analysis}

Based on the constructed rubric, we graded all questions answered by the students. The average and standard deviation of the mean of the collected data were then calculated. The difference between the average obtained for each of the questions was compared statistically by conducting a t-test a) between the same group of students who were tested at the beginning of their second year and then again at the start of their third year of the undergraduate Physics program, and b) between two separate groups of students who were tested when they entered their second year in the program, for two years in a row.

The students in Group I - sophomores who tested one year after taking Principles of Physics - had the average and SEM of $3.21 \pm 0.24$ for the first question, $1.60 \pm 0.25$ for the second question, and $1.73 \pm 0.35$ in the third question. It can be seen that one year after taking the Principles of Physics, students attained $64 \%$ of the maximum score in the first question, and $34 \%$ in the second and the third questions. Group II, the new group of sophomore students who were tested under the same conditions, one year after taking Principles of Physics, had a very comparable set of scores as compared with the first group. They earned $2.77 \pm 0.22,1.83 \pm 0.33,1.38 \pm$ 0.38 in Questions 1, 2, and 3 consequently. The results of statistical analysis indicated that the average score in these three questions are not statistically significant between the first and the second group of sophomore students who were tested two years in a row at the beginning of the Modern Physics class (Figure 1). In contrast, when the first group of students was re-tested two years after taking Principles of Physics, their calculated average scores were: $4.00 \pm 0.25$ for the first question, $2.93 \pm 0.47$ for the second question, and $2.06 \pm 0.54$ for the third question.

Figure 1: Horizontal: Questions 1, 2, and 3. Vertical: Average grade. Number of students in the first group (dark blue): N1=22. Number of students in the second group (orange): $\mathrm{N} 2=18$. The averages are not statistically different: Q1 (P-value $)=0.14, \mathrm{Q} 2(\mathrm{P}-$ value $)=0.62, \mathrm{Q} 3(\mathrm{P}$-value $)=0.56$. The threshold for the significance level was $\mathrm{P}$-value $<0.05$. 


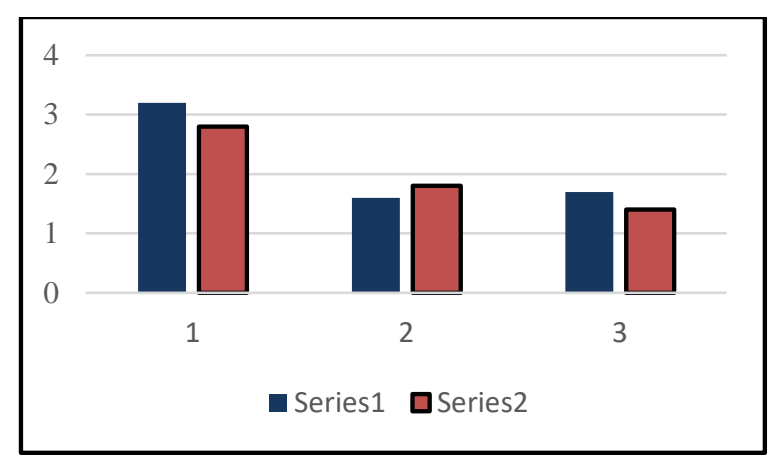

Figure 1. First and second group of sophomore students

As we compared the average scores between scores calculated one year and two years after they took the Principles of Physics course, it was observed that in the third year, they attained $80 \%$ of the total score in Question 1 and 60\% of the maximum score in Question 2. The calculated average scores measured in the second and the third year for this group of students was statistically significantly different. However, no significant change can be observed in the average score for the third question. The histograms of the measurements are presented in Figure 2.

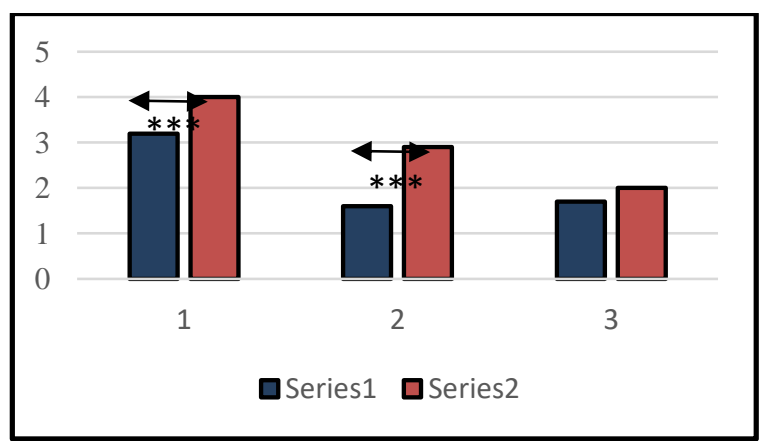

Figure 2. Same group of students/Two years in a row

Figure 2: Horizontal: Questions 1, 2, and 3. Vertical: Average grade. Number of students in the first group (dark blue): N1=22. Number of students in the second group (orange): $\mathrm{N} 2=16$. The differences in Q1 and Q2 are statistically significant: Q1 (P-value) = $0.03, \mathrm{Q} 2(\mathrm{P}$-value $)=0.01, \mathrm{Q} 3(\mathrm{P}$-value $)=0.62$. The threshold for the significance level was $\mathrm{P}$-value $<0.05$.

\section{Conclusion}

To ensure that the goals of higher education have been met, it is imperative that students' learning retention be assessed in order to evaluate teaching techniques, and further improve their understanding of the material. An assessment project may have multiple goals, ranging from evaluating students' learning in an individual course to the knowledge gained in a specific academic program. Collectively, all the efforts in this area grant us the opportunity to obtain reliable knowledge, information, and data that can provide insights in which teaching strategies can be improved in order to advance the academic program and benefit the students therein.

Like other disciplines, Science Education has played a significant role in providing different methods that can be implemented to deliver tools and approaches to instructors in order to evaluate students' learning and ameliorate it. In Physics, this effort has been extensive as it has offered many assessment methods, not only for introductory courses, but upper-division courses as well [16-18]. In addition, as the laboratory component is indelibly incorporated into a Physics program, various assessment techniques have been offered to evaluate and improve the practical learning of students [19].

Our assessment project was an approach designed to be implemented among a small group of learners. As we monitored the evolution of student learning in this study, we evaluated the learning retention of students one year and, consequently, two years after they learned a specific concept in Physics.

We hypothesized that, two years after learning that key Physics concept, and perhaps with less direct practice, the students' learning retention should not be significant. However, the obtained results indicate the opposite. Based on the results, a better understanding of the tested concept was confirmed. One year after learning the materials related to Work, the students did not go through an extensive review of the materials, or even solve direct problems related to the concept of "Work" during the course of Modern Physics.

However, they learned about the application of the concept to which they had been exposed before. During the sophomore course, students figured out that to learn the new concepts, some of the previously assimilated notions needed to be modified. They learned that the simple version of the concept cannot be properly utilized for more advanced materials. It seems that a learning intervention during the Modern Physics course stressing the modification and application of previously learned concepts can be lead to longer lasting learning.

While our study focused only on one of the key concepts of Physics, Work, it can be utilized for evaluating the evolving understanding of other concepts by students progressing through the undergraduate Physics program. One suggested course of action can be to map between Physics concepts that are learned across the courses and associated laboratories. Such an approach may clarify the connections between Physics concepts seen in various courses for the students. Creating a homogeneous course connectivity will illuminate links among courses and provide students with a smoother transition from lower-division to upperdivision courses and the efforts need to be made by instructors to make students aware of such 
connections and that the concept will be revisited again during the program. Altogether, a stronger introduction to Physics concepts along with an emphasis on course interdependence may potentially lead to a higher learning retention by the time students conclude their undergraduate Physics education. To further investigate the correlation between learning retention and learning intervention, we plan to conduct several assessment tests in order to collect comprehensive data to determine how to establish a stronger link among undergraduate Physics courses.

\section{Acknowledgment}

This work has received the review and approval of the office of Institutional Research Board of Seton Hall University.

\section{References}

[1] R. K. Thornton and D. R. Sokoloff, “Assessing student learning of Newton's laws: The force and motion conceptual evaluation and the evaluation of active learning laboratory and lecture curricula," Am. J. Phys. 66(4), 1998, 338-352.

[2] R. K. Thornton, D. Kuhl, K. Cummings, and J. Marx "Comparing the force and motion conceptual evaluation and the force concept inventory," Phys. Rev. ST Phys. Educ. Res. $5,2009,1-8$.

[3] L. Ding, R. Chabay, B. Sherwood, R. Beichner "Evaluating an electricity and magnetism assessment tool: Brief electricity and magnetism assessment," Phys. Rev. ST Phys. Educ. Res. 2, 2006, 010105-1-7.

[4] L. C. Hadfield and C. E. Wieman "Student interpretations of equations related to the first law of thermodynamics," J. Chem. Educ. 87 (7), 2010, 750-755.

[5] D.R. Sokoloff and R. K. Thornton, "Using interactive lecture demonstrations to create an active learning environment," Physics Teacher 35(6), 1998, 340-347.

[6] D.R. Sokoloff, P.W. Law, R.K. Thornton, "Real time Physics: Active learning labs transforming the introductory laboratory," European Journal of Physics 28 (3), 2007, 8394.

[7] P.W. Laws, M.C. Willis, D.R. Sokoloff, "Workshop physics and related curricula: A 25-year history of collaborative learning enhanced by computer tools for observation and analysis." Physics Teacher 53(7), 2015, 401-406.

[8] French, A. P., Vibrations and Waves, W. W. Norton and Company, New York, 1971, pp. $40-42$.

[9] Olenick, R. P., T. M. Apostol, and D. L. Goodstein, The Mechanical Universe: Introduction to Mechanics and Heat, Cambridge University Press, Cambridge, United Kingdom, 1985 , pp. $245-272$.
[10] Halliday, D., R. Resnick, and J. Walker, Fundamentals of Physics, Tenth Edition, John Wiley and Sons, Hoboken, New Jersey, 2013, pp. $151-165$.

[11] Young, H. D., and R. A. Freedman, Sears and Zemansky's University Physics with Modern Physics, Fourteenth Edition, Pearson, London, United Kingdom, (2016), pp. $196-212$.

[12] Serway, R. A., and J. W. Jewett, Physics for Scientists and Engineers, Sixth Edition, Thomson Brooks/Cole, Pacific Grove, California, 2004, pp. 183 - 196.

[13] Fishbane, P. M., S. G. Gasiorowicz, and S. T. Thornton, Physics for Scientists and Engineers with Modern Physics, Third Edition, Pearson Prentice Hall, Upper Saddle River, New Jersey, 2005, pp. $151-166$.

[14] Alonso, M., and E. J. Finn, Physics, Addison-Wesley Publishing, Reading, Massachusetts, 1992, pp. $157-169$.

[15] Ling, S. J., J. Sanny, and B. Moebs, University Physics, Volume 1, OpenStax, Houston, Texas, 2016, pp. 336 - 345.

[16] C. S. Wallace and S. V. Chasteen, "Upper-division students' difficulties with Ampere's law, Phys. Rev. ST Phys. Educ. Res. 6 (2), 2010, 020115-1-8.

[17] S. V. Chasteen and S. J. Pollock, "Transforming upperdivision electricity and magnetism," AIP Conf. Proc., 1064, 2008, 91-94.

[18] D. E. Meltzer, "Observations of general learning patterns in an upper-level thermal physics course, AIP Conf. Proc., 1179, 2009, 31-34.

[19] CA. C. K. Leung, B. Hashemi Pour, D. Reynold, S. Jerzak, "New assessment process in an introductory undergraduate physics laboratory: an exploration on collaborative learning," Assessment and Evaluation in Higher Education, 42(2), 2017, 169-181. 